\title{
Supplier Portfolio Management for IT Services Considering Diversification Effects
}

The increasing requirements for a need-oriented and flexible IT landscape are among the challenges which service-oriented architectures are supposed to meet. As a result, IT support of processes can be designed as a portfolio of individual IT services. The design of the processes is based on the selection decisions between IT services offered by different suppliers which potentially have to be taken into consideration. The scope of the formulated requirements for IT services investments, however, usually exceeds the available budget. Thus, companies face the challenge of allocating the budget to investments in the most promising IT services combination. In the present article a procedure model regarding value based management is developed which considers dependencies between the selection decisions. Subsequently, a decision logic for the heuristic solution is presented and its application is demonstrated by means of an illustrative case example.

DOI 10.1007/s12599-012-0203-y

\section{The Authors}

Florian Probst, M.Sc.

Prof. Dr. Hans Ulrich Buhl ( $\varangle)$

FIM Research Center Finance \&

Information Management

Department of Information Systems

Engineering \& Financial

Management

University of Augsburg

Universitätsstraße 12

86159 Augsburg

Germany

florian.probst@wiwi.uni-augsburg.de hans-ulrich.buhl@wiwi.uni-augsburg. de

url: http://www.fim-online.eu

Received: 2010-01-25

Accepted: 2011-05-30

Accepted after three revisions by

Prof. Dr. Bichler.

Published online: 2012-02-15

This article is also available in German in print and via http://www. wirtschaftsinformatik.de: Probst $F$, Buhl HU (2012) Lieferantenportfolio-Management für IT-Services unter Berücksichtigung von Diversifikationseffekten. WIRTSCHAFTSINFORMATIK. doi: 10.1007/s11576-012-0310-x.
Electronic Supplementary Material The online version of this article (doi: 10.1007/s12599-012-0203-y) contains supplementary material, which is available to authorized users.

(C) Gabler Verlag 2012

\section{Introduction}

In recent years companies have increasingly redesigned their IT landscape with the help of service-oriented architectures (SOAs) (Pahlke et al. 2010, p. 299). SOAs aim at, inter alia, achieving a higher customer orientation due to individualization as well as increased flexibility due to standardization (Gebauer and Lee 2008, p. 73; Gebauer and Schober 2006, p. 128; Singh and Huhns 2005, p. 78). For this purpose SOAs make it possible to design the support of individual process actions by means of IT services as an IT service portfolio (ITSP). An ITSP denotes a set of IT services which is to be used to support process actions on the basis of a specific infrastructure at a point in time or within a time span (vom Brocke and Sonnenberg 2007, p. 187). One IT service encapsulates a particular range of functionalities (regarding the granularity of IT services in SOAs cf., e.g., Braunwarth and Friedl 2010; Rud et al. 2007) and provides it for multiple use via defined in- terfaces (Erl 2005, pp. 384 ff; Krafzig et al. 2007, p. 60; Singh and Huhns 2005, pp. 76 ff; Papazoglou 2003). Thus, SOAs enable the support of process actions by means of IT services of several internal or external IT service providers (Braunwarth and Heinrich 2008, p. 100; Papazoglou 2003; Reichmayr 2003, p. 99 ff; vom Brocke et al. 2009, p. 226 f.). The design of the processes is brought about by the combination of the ITSP, i.e. mainly by selection decisions between IT services which potentially have to be taken into consideration (Schelp and Winter 2007, p. 1; Singh and Huhns 2005, p. 79; vom Brocke and Sonnenberg 2007, p. 188; vom Brocke et al. 2009, p. 227.) Due to the necessity of responding to, e.g., changing customer needs, developments in markets and technologies as well as legislative guidelines in a continuous and dynamic way (Setzer et al. 2008), many companies state a multitude of requirements for investment in IT services at ever shorter intervals (Brandl et al. 2007, p. 92; Kontogiannis et al. 2007, p. 5). Hence, there is not only an increasing time pressure regarding the valuation of investments and the implementation of IT services, but also "a multitude of design options whose economic consequences can hardly be estimated in rational terms without methodical support" (vom Brocke et al. 2009, p. 223). In addition, the scope of the favored investments in IT services usually exceeds the available budget, which is limited by monetary and non-monetary constraints such 
as a shortage of personnel or management resources (Wehrmann et al. 2006, p. 234). Therefore, especially those companies whose IT is strongly based on SOAs face the challenge of allocating the constrained budget to the most promising combination of investments in IT services. This requires a methodical valuation of the available IT services (cf. de Reyck et al. 2005, p. 526; vom Brocke et al. 2009, p. 223).

However, according to a global survey among 749 Chief Information Officers and Chief Executive Officers by the IT Governance Institute, only $50 \%$ of the surveyed companies have a clearly defined procedure for the valuation of IT (IT Governance Institute 2008, p. 31) which is necessary for the selection of the IT services. Instead of employing value based decision criteria, the selection is often made intuitively and it is subject to the decision-makers' affinity with IT (Kesten et al. 2007, p. 1). For prioritizing the available IT services

(1) a quantitative, multi-period procedure model for the purpose of maximizing the enterprise value in accordance with value based management is developed which considers interand intra-temporal dependencies of periodic selection decisions and

(2) a decision logic for the heuristic solution to the selection problem is presented and its practical application is demonstrated by means of an illustrative case example.

The procedure model is based on the Markowitz portfolio theory (Markowitz 1952). For that reason, fundamental problems regarding its transferability to issues of IT investment valuation are to be discussed critically (cf. Asundi and Kazman 2001; Kersten and Verhoef 2003; Verhoef 2002). Thus, especially the liquidity of the investment objects, which must exist at any given time, is a necessary pre-condition for the applicability of the portfolio theory. However, in the case of IT investments this applicability usually only exists up to the time of implementation (Verhoef 2002, p. 7; Zimmermann et al. 2008, p. 6). In the present article, though, the allocation of the limited budget towards the combination of favored investments in IT services which seems to be the most promising one in terms of returns and risks takes place before their implementation. For that reason they can be considered to be liquid at the time of portfolio optimization (cf. Zimmermann et al. 2008, p. 6).
The primary aim of this paper is to contribute to a better understanding of relationships in case of dependencies between portfolio positions and suppliers, especially with regard to the design of SOAs. The transferability of the results obtained in the illustrative case example to both larger problems and other companies or sectors, whose data quality is poorer than in the present case example, is discussed critically.

This article is organized as follows: Sect. 2 gives an overview of previous research. On this basis, requirements for a multi-period, quantitative procedure model that is used for prioritizing the available IT services is derived from literature. The procedure model as well as a decision logic which serves as a heuristic solution for the application of the model is presented in the following Sect. 3. In the subsequent Sect. 4 the application is demonstrated by means of an illustrative case example, which is based on the data of a German financial services provider. The last Sect. 5 summarizes the results and assesses them critically.

\section{Previous Studies and Requirements of the Procedure Model}

Numerous studies deal with the general valuation of IT investments (for an overview cf. vom Brocke et al. 2009, p. 226). In this context, especially the real options theory (cf. Bardhan et al. 2004; Benaroch and Kauffman 1999; Hawes and Duffey 2008) and the cost-utility analysis (cf. Jeffery and Leliveld 2004), which is widely used in practice, are of particular importance. However, a multitude of existing procedures neglect interdependencies between investments (e.g., mutual dependencies between IT services) which may significantly affect the portfolio risk (Wehrmann et al. 2006, p. 235). For that reason, the consideration of single investments - as it is often the case with general procedures for the valuation of investments, such as for the selection of software or other ITrelated acquisitions - is necessary but not sufficient in order to obtain an optimal ITSP (cf. Wehrmann et al. 2006, pp. 235 $\mathrm{ff})$. For this purpose, the consideration of dependencies is essential. Therefore, Verhoef (2002) transfers the discounted cash flow procedure to the valuation of IT investments where interdependencies can be considered implicitly by means of distribution assumptions, e.g., regarding process maturity (cf. Wehrmann et al. 2006, p. 237). However, a quantification of the risk in the form of a risk measure is not carried out, thus making a correct risk aggregation as to the portfolio risk impossible (Zimmermann 2008a, p. 359; 2008b, p. 463). Bardhan et al. (2004) draw on the above mentioned real options theory where risk is measured by means of a standard deviation and where dependencies between sequential investment decisions are considered. In contrast, Dörner (2003) and Wehrmann et al. (2006) use the Markowitz portfolio theory (Markowitz 1952). These studies also use the standard deviation as a risk measure, whereas the expected returns are incorporated with the help of the net present value. Due to the aggregation rules known from the portfolio theory, a correct aggregation of the expected returns and risks is possible while taking dependencies into consideration (Zimmermann 2008a, p. 359; 2008b, p. 463).

However, as to prioritizing the available IT services in companies whose IT landscape is based to a large extent on SOAs, the general procedures for the valuation of IT investments often prove to be too abstract (vom Brocke et al. 2009, p. 226). In contrast, studies concerning SOAs specifically deal with the decision support regarding the prioritization of the available IT services, but they often neglect the economic perspective (vom Brocke et al. 2009, p. 226). However, many authors call for a value based view on IT (vom Brocke et al. 2009, p. 224; Wehrmann et al. 2006, p. 234; Zimmermann 2008a, p. 358), which, so far, can only be found in a few studies on the design of SOAs (e.g., Thomas and vom Brocke 2010). Therefore, the present paper attempts to develop a quantitative, multi-period procedure model for the purpose of maximizing the enterprise value in accordance with value based management.

In order to prioritize the available IT services in accordance with a value based view, a target figure is necessary to measure the increase in enterprise value (Buhl et al. 2011, pp. 164 f; Coenenberg and Salfeld 2003, p. 3). This approach ensures the identification of the value contribution of an IT service. Apart from the expected return, however, risks also have to be taken into consideration (Zimmermann 2008b, p. 461), since neglecting them usually leads to a misallocation of resources (Maizlish and Handler 
2005, pp. $181 \mathrm{ff})$. In this context, risk does not necessarily imply danger or threat (downside risk), but it is rather a directionally independent deviation from the expected return as measured by symmetrical risk measures. In addition, the risk assessment is dependent on the decisionmaker's attitude towards risk (Zimmermann 2008b, p. 461). This results in the first requirement ( $R$ ) which should be fulfilled by a procedure model used for prioritizing available IT services:

R.1 The prioritization of the available IT services should depend on their respective contribution to an increase in the enterprise value (value contribution). When determining the value contribution, the expected return and risk are to be considered in accordance with the decisionmaker's attitude towards risk.

There can be dependencies between different IT services, e.g., with regard to availability (cf. Sect. 3.1), which affect the advantageousness of the selection (cf. Braunwarth and Heinrich 2008, p. 103; Diepold et al. 2011, p. 806; Zimmermann 2008 b, p. 462). In order to be able to show such dependencies regarding the prioritization of available IT services and to consider all significant interdependencies (Kargl 2000, p. 23), it is necessary to treat the IT landscape as a portfolio (Lacity and Willcocks 2003, p. 116). Thus, the second requirement can be derived:

R.2 When determining the value contribution of an IT service, dependencies between individual IT services should be examined. In order to be able to take them into account it is necessary to consider the company's IT landscape as a portfolio with existing IT services having to be incorporated during the valuation.

Thus, a procedure model for the prioritization of the available IT services is required which is able to determine the value contribution of a single IT service and the whole ITSP, while considering the expected return, risk, and dependencies between IT services. These can be obtained from both internal and external suppliers. Reichmayr (2003, pp. 99 ff) describes the term "outtasking" as the selection of IT services of external suppliers needed for the execution of individual process actions (cf. vom Brocke et al. 2009, p. 227). Moreover, Braunwarth and Heinrich (2008, p. 107) have shown that potential for optimization is forfeited by choosing only one supplier per process action, an approach that continues to be very common. However, if there is the possibility to assign individual executions of process actions independently of one another to various internal and/or external suppliers (e.g., out of 1000 executions of the process action "opening $a$ bank account" 600 are assigned to supplier $A$ and 400 to supplier $B$ ), the risk can be diversified. This leads to the third requirement:

R.3 The procedure model must ensure an integrated view of the prioritization of the available IT services, while determining at the same time the - according to a risk/return assessment - optimal individual participation of the suppliers in the execution of individual process actions.

In order to reach optimal decisions for all upcoming decision points as far as the end of the planning horizon and to avoid systematical, methodical bias during the process of prioritizing, the multiperiodicity of the problem and the resulting dynamic character have to be taken into account in an appropriate way (cf. de Reyck et al. 2005, p. 526). This leads to the fourth requirement:

R.4 The selection of IT services should be made - while considering periodic budget constraints - in such a way that the risk-adjusted value contributions, which correspond to the respective state of knowledge at the relevant decision points, are maximized over the planning horizon.

What ensues is a multi-period procedure model for the prioritization of the available IT services developed on the basis of these requirements.

\section{Formulation of the Procedure Model}

In the following a business case is assumed to be available for each existing IT service on hand (cf. Iqbal et al. 2007, p. 194). Apart from the variables contained therein, the model uses the documentation of the processes that potentially have to be supported and the process actions which are included. The documentation indicates, inter alia, which process actions can basically be supported by IT services. From service catalogues, which further specify these process actions, one can infer the expected demand as well as the expected payment surplus regarding the support of a process action by means of an IT service (cf. Blodig et al. 2006, pp. 473 ff;
Helmke and Dangelmaier 2008, p. 295). For this purpose, a pay-per-use pricing model for IT services is assumed, with the presented model also being suitable for differing pricing models (cf. Sect. 3.1). Table 1 gives an overview of all variables that have to be determined and suggests sources of procurement. Nevertheless, the collection of input parameters is a critical factor which may lead to limitations as to the application of the procedure model (cf. Sect. 5). Furthermore, it is to be assumed that it is already known whether IT services exist for the support of process actions or if the development of a suitable IT service is possible.

The definition of the requirements for IT services is usually recorded in a system specification, with strategic or legal restrictions or requirements which have to be taken into consideration (cf. Iqbal et al. 2007, p. 195). In doing so, a distinction has to be made between mandatory and optional requirements (Helmke and Dangelmaier 2008, p. 296). In the following, only those requirements are regarded as mandatory which indispensably have to be implemented, e.g., due to legal requirements. All other requirements exceeding the aforementioned scope are to be classified as autonomous optional requirements. Now, a prioritization of optional requirements for the implementation of IT services is to be executed at defined and recurring points in time, while mandatory requirements are taken into account. During this process, IT services of a company's ITSP can occur at four different stages of the life cycle. There are (1) identified IT services, which are described as a support of process actions, but have not been implemented yet; (2) requested IT services, which are implemented in the course of IT projects; (3) realized IT services, which have already served as a support of process actions; as well as (4) removed IT services, which are no longer available for the support of process actions. At the decision point, an ITSP consisting of realized IT services as well as identified IT services already exists. On the basis of this initial situation, a decision can be made as to which of the identified IT services are to be requested (decision point). During the phase between two successive decision points, the implementation of one or more authorized investments in IT services take place, or, respectively, the removal of IT services which are no longer needed (implementation phase). Changes in IT services can 


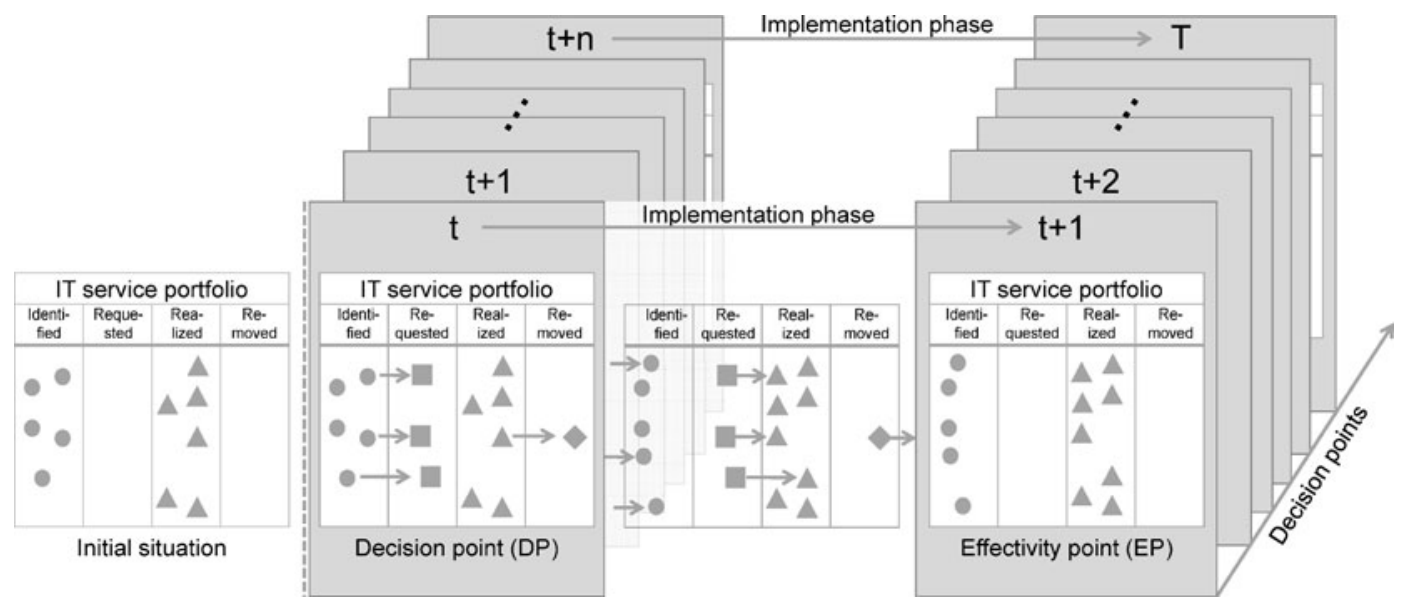

Fig. 1 IT service portfolio across several decision points

be made through the removal of an already realized IT service while at the same time requesting a new IT service in accordance with the desired specifications. Thus, at the next decision point, there is again an initial ITSP which consists of identified and realized IT services. In this way the changes of the ITSP, which were decided on at the decision point, are put into effect completely at the effectivity point. This procedure is repeated at each decision point (cf. Fig. 1).

\subsection{Hypotheses}

Taking the requirements formulated above into account, the following hypotheses as to the model are put forward; in doing so, all variables marked with the index $t$ are to be regarded as period related and, in contrast, all variables without the index $t$ are to be regarded as constant over all periods. Table 1 presents an overview of all variables that have to be determined as well as their possible sources of information.

The model is based on the following hypotheses:

A.1 In the company there is a set of process actions $m \in\{1,2, \ldots, M\}$ that is potentially supportable by IT; for the sake of simplicity this set of process actions is assumed to be static. The support of a process action $m$, which can be provided by the IT service $s_{m, n}$ of a supplier $n \in\{1,2, \ldots, N\}$, will presumably be required until the point in time $T_{m}$. The ITSP optimization is effected at the decision points (DP) $t \in\{0,1, \ldots, T\}$ until the end of the planning horizon $T$ with $T<\max _{m=1}^{M}\left(T_{m}\right)$. Also for the sake of simplicity, the implementation/inclusion of a new, requested IT service $s_{m, n}$ for the support of a process action $m$ or, respectively, the removal of an already realized IT service $s_{m, n}$ is to be completed after one period. Thus, after each DP $t$ the corresponding effectivity point (EP), which occurs in the subsequent period, has to be assumed to be $t+1 \in$ $\{1,2, \ldots, T+1\}$ in the following.

A.2 An IT service $s_{m, n}$ should be only considered if it is offered for the whole required period, i.e. from the EP $t+1$ to the end of the anticipated period at the point in time $T_{m}$. If the IT service $s_{m, n}$ of a supplier $n$, which is used for the support of a process action $m$ at the point in time $t$, has to be taken into consideration, then the element $a_{t, m, n} \in\{0,1\}$ of the $M \times N$ matrix $A_{t}$ (supply matrix at the point in time $t$ ) is one with regard to $t \in\left\{0, \max _{m=1}^{M}\left(T_{m}\right)\right\}$, otherwise it is zero. This ensures that all identified and realized IT services are considered during the optimization of the ITSP. If an IT service $s_{m, n}$ is removed at the end of the runtime $T_{m}$, then $a_{T_{m}+1, m, n}=0$ applies. If an IT service $s_{m, n}$ is removed before the end of the runtime $T_{m}$ at the DP $t$, then $a_{t+1, m, n}=0$ applies to the subsequent $\mathrm{EP} t+1$. The anticipated demand $q_{t, m} \in\{0,1, \ldots, Q\}$ for a process action $m$ per period between the two points in time $t$ and $t+1$ with $t \in\left\{0,1, \ldots, T_{m}\right\}$ occurs with the probability $d_{t, m} \in[0 ; 1]$ and it is zero with the probability $1-d_{t, m}$.

A.3 The budget $B_{t} \in \mathfrak{R}^{+}$for investments in IT services $s_{m, n}$, which is available at DP $t$, is limited. Therefore, it may be possible that the requested support can only be approved for a part of the process actions $m$. Thus, a decision should be taken during the optimization of the ITSP whether (1) a process action $m$ is to be supported by an IT service and, (2) if so, whether it is to be obtained from one or more suppliers $n$. With regard to the expected demand $d_{t, m}$. $q_{t, m}$ for an already realized IT service $s_{m, n}, x_{t, m, n} \in[0 ; 1]$ denote the shares in the execution - which have already been determined and which are obtained from a supplier $n$ for the support of a process action $m$ - at the decision point (DP) $t .{ }^{1}$ If a process action $m$ is supported by the IT service of one or more suppliers $n$ at the point in time $t$, then $\sum_{n=1}^{N} x_{t, m, n}=1$ is valid. In addition, a share $x_{t, m, n}$, which has already been determined, is to be constant over the remaining period of the IT service $s_{m, n}$ until its removal at the point in time $T_{m}$. Thus, the decision variables of the model are - at each DP $t$ - the shares $x_{t+1, m, n}$ in the execution of an identified IT service $s_{m, n}$ with reference to its expected demand $d_{t+1, m} \cdot q_{t+1, m}$ from the effectivity point (EP) $t+1$ onwards.

In case a process action $m$ is supported, payments for investments incur in the

${ }^{1}$ In the same way, also IT services used for the fulfillment of mandatory requirements can be considered in this model. 
Table 1 Overview of all variables to be determined and possible sources of information

\begin{tabular}{|c|c|c|c|}
\hline Input parameter & Variable & Unit & Source of information \\
\hline Anticipated demand & $q_{t, m}$ & Executions/period & Estimation by the company \\
\hline $\begin{array}{l}\text { Occurrence probability of the anticipated } \\
\text { demand }\end{array}$ & $d_{t, m}$ & - & $\begin{array}{l}\text { Experience from preceding periods and market } \\
\text { analyses }\end{array}$ \\
\hline Budget & $B_{t}$ & $\begin{array}{l}\text { Monetary unit } \\
(\mathrm{MU}) / \text { period }\end{array}$ & Defined by the company \\
\hline Payments for investments & $I_{m, n}$ & MU & $\begin{array}{l}\text { Comparison of offers from various suppliers or } \\
\text { internal prices of the own IT subsidiary }\end{array}$ \\
\hline $\begin{array}{l}\text { Variable payments for the use of an IT } \\
\text { service }\end{array}$ & $p_{t, m, n}$ & MU/execution & $\begin{array}{l}\text { Comparison of offers of various suppliers or } \\
\text { internal prices of the own IT subsidiary }\end{array}$ \\
\hline $\begin{array}{l}\text { Cash flow for successful execution of a } \\
\text { process action }\end{array}$ & $g_{t, m}$ & MU/execution & Estimation by the company \\
\hline Expected availability of an IT service & $E\left(\tilde{w}_{m, n}\right)$ & - & $\begin{array}{l}\text { Medium availability guaranteed in advance by the } \\
\text { supplier or own IT subsidiary in the Service Level } \\
\text { Agreement (SLA) }\end{array}$ \\
\hline Availability variance of an IT service & $\operatorname{Var}\left(\tilde{w}_{m, n}\right)$ & - & $\begin{array}{l}\text { By means of empirical values and methods used } \\
\text { for valuation of suppliers (cf. Braunwarth and } \\
\text { Heinrich 2008) }\end{array}$ \\
\hline Costs of IT service failure & $k_{t, m, n}$ & MU/execution & $\begin{array}{l}\text { Estimation by means of the costs for the } \\
\text { alternative execution (e.g., manual execution) of } \\
\text { the necessary process actions or by means of a } \\
\text { forecast of the lost payment surplus }\end{array}$ \\
\hline $\begin{array}{l}\text { Correlation between the expected } \\
\text { availabilities }\end{array}$ & $\rho$ & - & $\begin{array}{l}\text { Estimation by means of empirical values or by } \\
\text { means of the own IT subsidiary }\end{array}$ \\
\hline Risk aversion parameter & $b$ & - & Determined by the company \\
\hline Rate of interest (calculatory) & $i_{\text {calc }}$ & - & Rate of interest used in the company or sector \\
\hline
\end{tabular}

first instance. If the IT service $s_{m, n}$ is provided by the company itself, these payments for investments comprise costs of implementation and/or inclusion (e.g., if an already existing IT service is reused); if an IT service is obtained from an external supplier, they consist of inclusion costs only.

A.4 Payments in advance for investments $I_{m, n} \in \mathfrak{R}^{+}$in the form of costs of implementation and/or inclusion incur for each IT service $s_{m, n}$, which is required for the support of a process action $m$, at DP $t$. For the sake of simplicity, no costs should incur for the removal of an IT service at the end of its runtime $T_{m}$.

During the execution of a realized IT service, attributable outgoing and incoming payments incur. The outgoing payments can be determined comparatively easily, especially in case of pay-per-use pricing models. Further possible pricing models can be found in Boles and Schmees (2003), whereas Braunwarth and Heinrich (2008, p. 102) demonstrate how alternative pricing models can be used. In contrast to that, the payments which incur during the execution of a realized IT service can be determined, e.g., by means of the saving potential that can be accomplished in comparison to the manual execution of the process action. Other ways of quantifying the outgoing and incoming payments as to IT services as well as the related uncertainty of the data can be found in, e.g., Brandl et al. (2007), Diao and Bhattacharya (2008), Dreifus et al. (2007, pp. 20 f), Thomas and vom Brocke (2010, pp. 76 ff), and Kesten et al. (2007).

A.5 By using a realized IT service $s_{m, n}$, variable outgoing payments $p_{t, m, n} \in$ $\mathfrak{R}^{+}$for one unit of the IT service $s_{m, n}$ incur when the IT service $s_{m, n}$ is provided by the company itself as well as when it is obtained from an external supplier (pay-per-use pricing model). If further fixed costs incur due to the use of a realized IT service $s_{m, n}$, the possibility of turning fixed costs into variable costs is assumed. The successful execution of a process action $m$ generates incoming payments in the amount of $g_{t, m} \in$ $\mathfrak{R}^{+}$, which can be attributed to the support provided by the realized IT service $s_{m, n}$. Thus, the payment surplus in advance $r_{t, m, n} \in \mathfrak{R}^{+}$for each successful execution of a process action $m$, which is supported by the
IT service $s_{m, n}$, can be derived from $r_{t, m, n}=g_{t, m}-p_{t, m, n}$.

In order to ensure the desired availability of the IT service, availability guarantees and penalty payments in case of nonprovision are usually negotiated with the suppliers and stipulated in the Service Level Agreements (SLAs) (cf. Trienekens et al. 2004). Still, it has to be assumed that IT services are not always provisioned without delay or lack of quality. Usually, such operational risks are measured as Poisson-distributed random variables (Prokein 2008, pp. 43 ff). However, due to the availability which is expected to be high on average and the anticipated multitude of executions of an IT service, the normal distribution can be applied by way of approximation (cf. Schlittgen 2003, p. 243). Therefore, the following is assumed regarding the model (cf. Braunwarth and Heinrich 2008, p. 103):

A.6 The probability $\tilde{w}_{m, n} \in[0 ; 1]$ that a realized IT service $s_{m, n}$ will be available within the stipulated time period and in the agreed quality is depicted by normally distributed random variables with the expected value $E\left(\tilde{w}_{m, n}\right)$ and the standard de- 


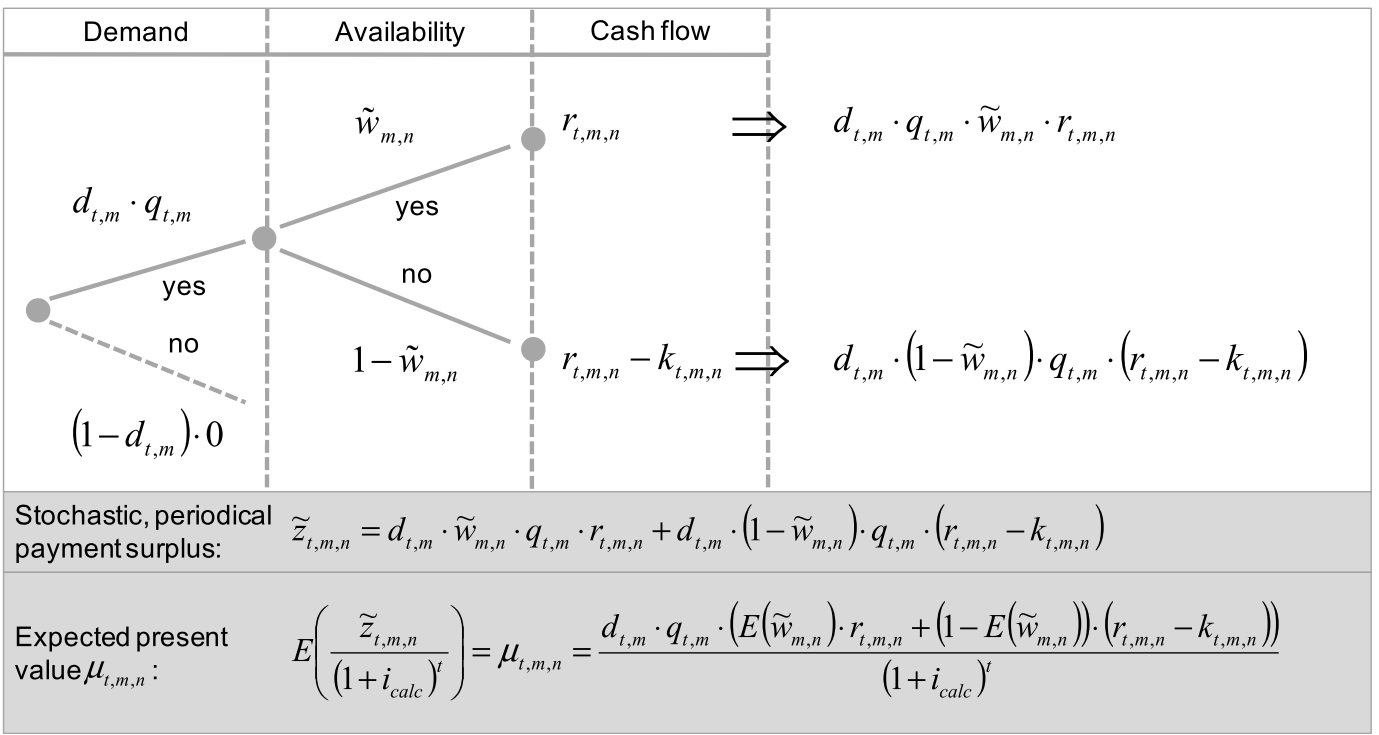

Fig. 2 Composition of the expected present value of the periodical payment surpluses of an IT service

viation $\sqrt{\operatorname{Var}\left(\tilde{w}_{m, n}\right)} \cdot{ }^{2}$ It is assumed that the probability of the availability $\tilde{w}_{m, n}$ is defined in the SLA and that it remains constant until the end of the IT service's period at the point in time $T_{m}$. As to the probability $\tilde{w}_{m, n}, \tilde{w}_{m, n}=1$ means that the IT service $s_{m, n}$ is available in any case, and in the case of $\tilde{w}_{m, n}=0$ it is not available at all.

A.7 In case of the non-availability of the requested IT service $s_{m, n}$, additional outgoing payments in advance amounting to $k_{t, m, n} \in \mathfrak{R}^{+}$incur (e.g., by means of process failure or manual processing). It is assumed that any agreed penalty payments are already deducted.

From these assumptions it can be derived that in the period between $t$ and $t+1$ an IT service $s_{m, n}$ will be requested $q_{t, m}$ times with a probability of $d_{t, m}$, and that it will not be requested with a counter-probability of $1-d_{t, m}$. In the former case, the requested IT service $s_{m, n}$ is available with a probability of $\tilde{w}_{m, n}$ and it is not available with a probability of $1-\tilde{w}_{m, n}$. In case of availability there will be a payment surplus for the company amounting to $r_{t, m, n}$; in case of nonavailability additional payments in the amount of $k_{t, m, n}$ are deducted and there will be a payment surplus of $r_{t, m, n}-$ $k_{t, m, n}$ (cf. Fig. 2).
A.8 Due to the support of process action $m$ by means of the IT service $s_{m, n}$ of supplier $n$, there are stochastic, periodical payment surpluses $\tilde{z}_{t, m, n}$ starting from DP $t$ for realized IT services and from EP $t+1$ for newly requested IT services to the end of the anticipated runtime $T_{m}$ (cf. Fig. 2). For the purpose of achieving comparability of the periodical payment surpluses, which are dependent on DP $t$, the expected values of the stochastically periodical payment surpluses $\tilde{z}_{t, m, n}$ are consistently discounted to $t=0$ with the given rate of interest $i_{\text {calc }} \in \Re^{+}$.

Thus, the expected present value of the periodical payment surpluses of each IT service $s_{m, n}$ at the point in time $t$ is calculated as follows:

$$
\begin{aligned}
\mu_{t, m, n}= & {\left[d _ { t , m } \cdot q _ { t , m } \cdot \left(E\left(\tilde{w}_{m, n}\right) \cdot r_{t, m, n}\right.\right.} \\
& +\left(1-E\left(\tilde{w}_{m, n}\right)\right) \\
& \left.\left.\cdot\left(r_{t, m, n}-k_{t, m, n}\right)\right)\right] \\
& \cdot\left[\left(1+i_{c a l c}\right)^{t}\right]^{-1} .
\end{aligned}
$$

The expected present value of the entire ITSP $\mu_{P}$ at DP $t=0$ results from the sum of the weighted expected present values of the periodical payment surpluses $\mu_{t, m, n}$ of all realized and newly requested IT services $s_{m, n}$, which have to be considered and which are due from EP $t+1$ onwards, with this sum being aggregated across all process actions and suppliers and reduced by the outgoing payments in advance for investments $I_{m, n}$, which are also discounted to $t=0$ :

$$
\begin{aligned}
\mu_{P}= & \sum_{m=1}^{M} \sum_{n=1}^{N} \sum_{t=0}^{T_{m}-1}\left(x_{t+1, m, n} \cdot a_{t+1, m, n}\right. \\
& \cdot \mu_{t+1, m, n}-\frac{I_{m, n}}{\left(1+i_{c a l c}\right)^{t}} \\
& \cdot\left(1-\operatorname{sgn}\left[\left(1-\operatorname{sgn}\left[x_{t+1, m, n}\right]\right)\right.\right. \\
& \left.\left.\left.+\operatorname{sgn}\left[x_{t, m, n}\right]\right]\right)\right)
\end{aligned}
$$

with the constraints: $x_{t+1, m, n}=x_{h, m, n}=$ konst. $>0 \forall t \leq h \leq T_{m}, m, n$, if $h \geq 0$, with $h$ being defined as $h=\min \{v \in$ $\left.\left\{0, \ldots, T_{m}\right\}: x_{v, m, n}>0\right\}$.

The signum function helps to achieve that the outgoing payments in advance for investments $I_{m, n}$ are entirely taken into consideration only in the selection period and also if an IT service is only proportionally obtained from one supplier. In addition, the constraints ensure that - as formulated in A.3 solely the shares $x_{t+1, m, n}$ of the identified IT services are determined at DP $t$ and that already existent shares $x_{v, m, n}$ with $0 \leq v \leq t$ are regarded to be constant. Since the probabilities $\tilde{w}_{m, n}$ are distributed normally, this also applies to the stochastic, periodical payment surpluses $\tilde{z}_{t, m, n}$. The corresponding standard deviation is determined by $\sigma_{t, m, n}$ and can be calculated as follows:

\footnotetext{
${ }^{2}$ It has to be assumed that the related density function will be very slender, because there is usually an SLA for each IT service, which ensures a very high availability of the IT service $(95-99 \%)$. As a consequence $E\left(\tilde{w}_{m, n}\right)$ is usually between 0.95 und 0.99 . Thus, already in case of a $\tilde{w}_{m, n}$-value, which corresponds to the availability guaranteed in the SLA, the density function has very flat tails. Therefore, the edges of the domain $\tilde{w}_{m, n}<0$ and $\tilde{w}_{m, n}>1$ are not to be considered due to a lack of plausibility and the flat tails of the density function are notionally removed.
} 
$\sigma_{t, m, n}=\frac{d_{t, m} \cdot q_{t, m} \cdot k_{t, m, n}}{\left(1+i_{\text {calc }}\right)^{t}} \cdot \sqrt{\operatorname{Var}\left(\tilde{w}_{m, n}\right)}$.

Due to shared resources, such as databases of third-party suppliers, the probability of availability is not independent in reality, even in case of competing IT services of various suppliers.

A.9 There are linear dependencies between the probabilities of availability $\tilde{w}_{m, n_{i}}$ and $\tilde{w}_{m, n_{j}}$ regarding two IT services $s_{m, n_{i}}$ and $s_{m, n_{j}}$ of two different suppliers $n_{i}$ and $n_{j}$ with $n_{i} \neq$ $n_{j}$, which can be employed for the same process action $m$. They are depicted by means of the correlation coefficient $\rho\left(s_{m, n_{i}}, s_{m, n_{j}}\right) \in[-1 ; 1]$.

In addition, due to shared resources of one supplier, such as a server which is used for various IT services, the probability of availability regarding two IT services of one supplier is usually not independent.

A.10 There are linear dependencies between the probabilities of availability $\tilde{w}_{m_{k}, n}$ and $\tilde{w}_{m_{l}, n}$ regarding two IT services $s_{m_{k}, n}$ and $s_{m_{l}, n}$ of the same supplier $n$ which are used for the support of different process actions $m_{k}$ and $m_{l}$ with $m_{k} \neq m_{l}$; these linear dependencies are depicted by the correlation coefficient $\rho\left(s_{m_{k}, n}, s_{m_{l}, n}\right) \in[-1 ; 1]$.

A.11 With respect to the model it is assumed that the risk of the entire ITSP is measured by means of the variance $\sigma_{P}^{2}$. This corresponds to the weighted sum of all covariances of the individual stochastic periodical payment surpluses of the IT services $s_{m, n}$, which are part of the ITSP in relation to the stochastic periodical payment surpluses of the entire ITSP.

Thus, weighted with the shares $x_{t+1, m, m}$ of the IT services $s_{m, n}$, which have already been realized or newly requested at EP $t+1$, the following equation can be derived (cf. Bamberg et al. 2006):

$$
\begin{aligned}
\sigma_{P}^{2}= & \sum_{m_{k}=1}^{M} \sum_{n_{i}=1}^{N} \sum_{t_{p}=0}^{T_{m_{k}}-1} \sum_{m_{l}=1}^{M} \sum_{n_{j}=1}^{N} \\
& \cdot \sum_{t_{q}=0}^{T_{m_{l}}-1} x_{t_{p}+1, m_{k}, n_{i}} \cdot a_{t_{p}+1, m_{k}, n_{i}} \\
& \cdot x_{t_{q}+1, m_{l}, n_{j}} \cdot a_{t_{q}+1, m_{l}, n_{j}} \cdot \sigma_{t_{p}+1, m_{k}, n_{i}} \\
& \cdot \sigma_{t_{q}+1, m_{l}, n_{j}} \cdot \rho\left(s_{m_{k}, n_{i}}, s_{m_{l}, n_{j}}\right)
\end{aligned}
$$

with the constraints: $x_{t+1, m, n}=x_{h, m, n}=$ konst. $>0 \forall t \leq h \leq T_{m}, m, n$, if $h \geq 0$, with $h$ being defined as $h=\min \{v \in$ $\left.\left\{0, \ldots, T_{m}\right\}: x_{v, m, n}>0\right\}$.

The aims of a value based ITSP are both "to maximize the expected return" and "to minimize the risk". Since both aims cannot be achieved at the same time - a fact that has been discussed sufficiently in relevant literature - a preference function is necessary which is in accordance with the $(\mu, \sigma)$ rule (cf. requirement R.1) in order to determine the ITSP with the highest value contribution. As to the modeling the following is assumed:

A.12 For the decision-maker there is a utility function which is compatible with the Bernoulli principle and which assigns a value to each ITSP. The decision-maker always chooses the ITSP with the maximum preference function value. When determining the maximum preference function value, the expected present value $\mu_{P}$ and the risk $\sigma_{P}^{2}$ have to be taken into consideration in accordance with the decision-maker's attitude towards risk.

In doing so, the decision-maker's aim is to choose - in accordance with his attitude towards risk and in consideration of the budget constraint - that ITSP which maximizes the risk-adjusted value contributions corresponding to the respective state of knowledge at the DPs across the planning horizon. Schneeweiß (1967) as well as Bamberg et al. (2006) have shown that in case of a constellation as indicated in assumptions A.6 and A.12 only a preference function of the following type is compatible with the Bernoulli principle:

$\varphi\left(\mu_{P}, \sigma_{P}\right)=\mu_{P}-\frac{b}{2} \cdot \sigma_{P}^{2} \rightarrow \max !$

with the constraints: $x_{t+1, m, n}=x_{h, m, n}=$ konst. $>0 \forall t \leq h \leq T_{m}, m, n$, if $h \geq 0$, with $h$ being defined as $h=\min \{v \in$ $\left.\left\{0, \ldots, T_{m}\right\}: x_{v, m, n}>0\right\}$ and

$$
\begin{aligned}
& \sum_{m=1}^{M} \sum_{n=1}^{N} I_{m, n} \cdot\left(1-\operatorname{sgn}\left[\left(1-\operatorname{sgn}\left[x_{t, m, n}\right]\right)\right.\right. \\
& \left.\left.\quad+\operatorname{sgn}\left[x_{t-1, m, n}\right]\right]\right) \leq B_{t} \quad \forall t .
\end{aligned}
$$

The parameters $\mu_{P}$ und $\sigma_{P}^{2}$ result from the formulas (3.2) and (3.4), respectively. The risk aversion parameter $b \in \Re$, the Arrow-Pratt measure, represents the decision-maker's attitude towards risk (Arrow 1965; Pratt 1964); with $b>0$ meaning risk aversion, $b=0$ meaning risk neutrality and $b<0$ meaning risk affinity. Moreover, the constraint

$$
\begin{aligned}
& \sum_{m=1}^{M} \sum_{n=1}^{N} I_{m, n} \cdot\left(1-\operatorname{sgn}\left[\left(1-\operatorname{sgn}\left[x_{t, m, n}\right]\right)\right.\right. \\
& \left.\left.\quad+\operatorname{sgn}\left[x_{t-1, m, n}\right]\right]\right) \leq B_{t} \quad \forall t
\end{aligned}
$$

ensures that the periodical budget constraints are considered at each DP $t$.

\subsection{Heuristic Procedure for the Model's Practical Application}

Due to the dynamic character of the decision problem, the optimization of the ITSP is dependent on all previous decisions at each DP $t$ and in turn affects the subsequent possible alternatives. In order to solve the stochastic dynamic optimization problem presented in formula (3.5) and to consider the interdependencies between the DP $t$, the dynamic optimization according to Bellman (1957) can be applied. However, its application is problematic because of the necessity of modeling the problem entirely and providing all data. Usually, this problem cannot be coped with in practice since the data and hence the optimization problem itself is subject to its own dynamics during the course of time. From today's point of view it is difficult to predict, e.g., which IT services will be identified and requested in the future. Thus, it is questionable to what extent the high complexity and the significant calculative effort, which are associated with dynamic optimization, can be justified if the required data basis, which determines future alternatives of action and thus the optimization problem, is fraught with such a high forecast uncertainty. For this reason, a decomposition of the dynamic decision problem formulated in Sect. 3.1 seems to be an alternative. The basic idea of this is the fragmentation of the dynamic optimization problem presented in formula (3.5) into various individual problems. As to each of these problems, the relevant values at the DP $t$ are discounted to $t$ so that - to be more precise - we have to talk about a present value and time related optimization. For this purpose, the portfolios are assumed to remain constant across the planning horizon. Thus, the ex-ante consideration of a subsequent adaptability is ignored. The adjusted objective function which is based on formula (3.5) can be found in Appendix 1. Thus, in contrast to the exact closed-loop optimization, the dynamic optimization problem is solved in a time-related way. As a result, possible inter-temporal interdependencies between the DP $t$ are not 
considered, leading to a heuristic character of the solution. The detailed procedure regarding the optimization of the ITSP for each DP $t$ and the determination of the required parameters can also be found in Appendix 1.

\section{Case Example and Interpretation of Results}

In the following, the procedure described in Sect. 3 is presented by using the example of a financial services provider. For reasons of confidentiality the explanation remains anonymous and the figures employed have been modified slightly.

\subsection{Introduction of the Case Example}

The financial services provider is positioned as a multi-channel bank in the German market. In order to standardize and improve its processes the service provider aims to increasingly convert its IT landscape in accordance with SOAs. In this course, individual process actions of customer advice and sales processes shall be supported by IT services. In order to implement the IT investments, which have been requested by the respective departments by means of appropriate business cases, the financial services provider carries out two releases per year. In this context, the term release denotes the implementation of one or more approved investments in IT services. For this purpose, a budget in MU (monetary unit) is available for the specification, development, testing, and implementation of new IT services (excluding current costs) for each release at each DP $t$ (cf. Table 2).

At the first DP $t=0$ the redesign of the process of opening an account is focused on. The process actions "check address data", "enter SCHUFA/InfoScore ${ }^{3}$ information", and "report account to SCHUFA" are chosen as examples from this process. In the context of designing a dashboard (online application used for the visualization of information) with a decision support for stock broking there is the set of process actions "show analyst valuation", "show share signals", and "show charts", which can be chosen from with regard to the next release at DP $t=$ 1. At the last DP $t=T=2$ considered at this point, the respective departments

Table 2 Available budget

\begin{tabular}{lccc}
\hline Decision point (DP) $t$ & $t=0$ & $t=1$ & $t=T=2$ \\
\hline Budget $B_{t}$ in MU & 2000 & 3000 & 3000 \\
\hline
\end{tabular}

have requested IT services for the implementation of the process actions " $e x$ ecute identity check", "determine opportunities/risks", and "start e-mail campaign". These IT services are connected with the design of a so-called "Internet ClientFilial-System"4 with an integrated customer relationship management (CRM) tool.

Each of these process actions can be executed by an identified IT service which is either obtained from the own IT subsidiary or from two external suppliers (e.g., SCHUFA, which provides access by means of a XML-Gateway). However, the sum of MUs required for the implementation of the requested IT services exceeds the budget which is available at the DP by up to $50 \%$. As a consequence, the IT services, which have to be newly developed or to be obtained from external suppliers, have to be chosen on the basis of the submitted business cases. Thus, the financial services provider has to deal with the question of which of the identified IT services are to be realized until the next EP and whether they are to be obtained from one or more suppliers proportionally. For this purpose, the data which were provided in the business cases and which provide information on the expected frequency in which an IT service is used, the probability to which it will be requested, and the expected incoming payment surpluses for each use of the service serve as the basis for the decision. The prices of the IT services can be determined relatively easily by means of suppliers' offers or the IT subsidiary's internal prices. The same applies to reliability and, consequently, the expected probabilities of availability. Here the suppliers guarantee a medium availability in the SLAs (possibly including a fluctuation range). Table 1 gives an overview of the variables that have to be determined and their possible sources of information. On the basis of these data, the input parameters $\hat{\mu}_{\tau, m, n}$ and $\hat{\sigma}_{\tau, m, n}$ at DP $t=0$ have been determined for the financial services provider using a rate of interest of $i_{\text {calc }}=0.10$. For the purpose of demonstration, Table 3 provides an extract of the results.

\subsection{Application and Interpretation of the Results}

With the help of the data basis, which was determined together with the financial services provider, the procedure described in Sect. 3.2 (cf. Appendix 1) was carried out. The results regarding a risk-neutral (cf. Table 4), a risk-averse (cf. Table 5), and a strongly risk-averse decision-maker (cf. Table 6) are presented below for the purpose of demonstration. The values in the cells indicate the determined shares in the execution of an identified IT service with regard to its expected demand from EP $t+1$ onwards (cf. assumption A.3). The IT service of, e.g., supplier 3 is supposed to provide IT support for $100 \%$ of all executions of process action 1 from EP $t=1$ onwards (cf. Table 4). The white cells include the shares of identified IT services determined at DP $t$. The gray cells either have not had to be considered yet at DP $t$ or they include shares of IT services that have already been realized and which are regarded to be constant until the end of the runtime or, respectively, until their removal (cf. assumption A.3).

Especially three results are striking:

\section{Diversification}

The risk-neutral decision-maker (and this would also have been the financial services provider's previous decision) would for each process action solely employ that IT service which has the maximum present value and would always assign a realized IT service entirely to one supplier. The more attention is paid to the risk, the more cautious the decision-makers investment and diversification will be. While in the case of risk aversion two suppliers are used for one process action (process action 6 in Table 5), two process actions (process actions 5 and 8 in Table 6) are supported by IT services of two suppliers in case of

\footnotetext{
${ }^{3}$ German companies that provide information on the creditworthiness of potential new customers.

${ }^{4}$ Internet based system which is intended to improve efficiency as to customer service.
} 
Table 3 Extract of the calculated input parameters $\hat{\mu}_{\tau, m, n}$ and $\hat{\sigma}_{\tau, m, n}$ for $t=0$

\begin{tabular}{|c|c|c|c|c|c|c|}
\hline \multirow{2}{*}{$\begin{array}{l}\text { Point in time } \tau=t+1 \\
\text { Supplier } n\end{array}$} & \multicolumn{3}{|l|}{$\tau=1$} & \multicolumn{3}{|c|}{$\tau=T_{m}=6$} \\
\hline & Supplier 1 & Supplier 2 & Supplier 3 & Supplier 1 & Supplier 2 & Supplier 3 \\
\hline Expected present value $\hat{\mu}_{\tau, 1, n}$ & 1036.66 & 932.05 & 1216.19 & 965.57 & 868.31 & 1133.13 \\
\hline Expected present value $\hat{\mu}_{\tau, 2, n}$ & 856.67 & 924.05 & 1055.33 & 607.92 & 655.81 & 748.98 \\
\hline Expected present value $\hat{\mu}_{\tau, 3, n}$ & 917.87 & 983.65 & 1063.89 & 607.92 & 651.52 & 704.69 \\
\hline Standard deviation $\hat{\sigma}_{\tau, 1, n}$ & 2.09 & 2.26 & 1.57 & 1.95 & 2.10 & 1.46 \\
\hline Standard deviation $\hat{\sigma}_{\tau, 2, n}$ & 1.22 & 1.30 & 2.21 & 0.86 & 0.92 & 1.57 \\
\hline Standard deviation $\hat{\sigma}_{\tau, 3, n}$ & 2.05 & 2.40 & 3.84 & 1.35 & 1.59 & 2.54 \\
\hline
\end{tabular}

Table 4 Tableau of results for the case example as to $b=0$ (risk-neutral decision-maker)

\begin{tabular}{|c|c|c|c|c|c|c|c|c|c|}
\hline \multirow[t]{2}{*}{ Decision point (DP) $t$} & \multicolumn{3}{|l|}{$t=0$} & \multicolumn{3}{|l|}{$t=1$} & \multicolumn{3}{|l|}{$t=2$} \\
\hline & Supplier 1 & Supplier 2 & Supplier 3 & Supplier 1 & Supplier 2 & Supplier 3 & Supplier 1 & Supplier 2 & Supplier 3 \\
\hline Process action 1 & 0 & 0 & 1 & 0 & 0 & 1 & 0 & 0 & 1 \\
\hline Process action 2 & 0 & 0 & 1 & 0 & 0 & 1 & 0 & 0 & 1 \\
\hline Process action 3 & 0 & 0 & 0 & 1 & 0 & 0 & 1 & 0 & 0 \\
\hline Process action 4 & - & - & - & 0 & 1 & 0 & 0 & 1 & 0 \\
\hline Process action 5 & - & - & - & 0 & 0 & 0 & 0 & 0 & 0 \\
\hline Process action 6 & - & - & - & 0 & 1 & 0 & 0 & 1 & 0 \\
\hline Process action 7 & - & - & - & - & - & - & 0 & 0 & 1 \\
\hline Process action 8 & - & - & - & - & - & - & 0 & 0 & 0 \\
\hline Process action 9 & - & - & - & - & - & - & 0 & 0 & 1 \\
\hline Exploited budget & \multicolumn{3}{|c|}{$2000(100 \%)$} & \multicolumn{3}{|c|}{$3000(100 \%)$} & \multicolumn{3}{|c|}{$2800(93.3 \%)$} \\
\hline
\end{tabular}

Table 5 Tableau of results for the case example as to $b=40$ (risk-averse decision-maker)

\begin{tabular}{|c|c|c|c|c|c|c|c|c|c|}
\hline \multirow[t]{2}{*}{ Decision point (DP) $t$} & \multicolumn{3}{|l|}{$t=0$} & \multicolumn{3}{|l|}{$t=1$} & \multicolumn{3}{|l|}{$t=2$} \\
\hline & Supplier 1 & Supplier 2 & Supplier 3 & Supplier 1 & Supplier 2 & Supplier 3 & Supplier 1 & Supplier 2 & Supplier 3 \\
\hline Process action 1 & 0 & 0 & 1 & 0 & 0 & 1 & 0 & 0 & 1 \\
\hline Process action 2 & 1 & 0 & 0 & 1 & 0 & 0 & 1 & 0 & 0 \\
\hline Process action 3 & 0 & 0 & 0 & 1 & 0 & 0 & 1 & 0 & 0 \\
\hline Process action 4 & - & - & - & 0 & 0 & 1 & 0 & 0 & 1 \\
\hline Process action 5 & - & - & - & 0 & 1 & 0 & 0 & 1 & 0 \\
\hline Process action 6 & - & - & - & 0 & 0 & 0 & 0.39 & 0.61 & 0 \\
\hline Process action 7 & - & - & - & - & - & - & 0 & 0 & 0 \\
\hline Process action 8 & - & - & - & - & - & - & 0 & 0 & 0 \\
\hline Process action 9 & - & - & - & - & - & - & 0 & 0 & 0 \\
\hline Exploited budget & \multicolumn{3}{|c|}{$2000(100 \%)$} & \multicolumn{3}{|c|}{$2900(96.7 \%)$} & \multicolumn{3}{|l|}{$2400(80 \%)$} \\
\hline
\end{tabular}

strong risk aversion. This makes clear that the diversification of the default risk becomes more important as risk aversion increases.

2. Selection of IT services and exhaustion of the budget

The IT services which are selected by the risk-neutral decision-maker and which simultaneously have the highest present value and a higher default risk make up only a small part of the ITSP as the risk aversion increases. In addition, the exhaustion of the available budget steadily decreases as risk aversion increases, i.e. fewer process actions are supported by IT services and potential cost savings and improvements in efficiency are not achieved.

3. Portfolio risk

For every decision-maker - the riskneutral, the risk-averse as well as the strongly risk-averse decision-maker the aggregation of the periodical ITSP optimization (cf. step 3 of the procedure presented in Appendix 1) produces the expected present value of the ITSP, the portfolio risk, and the value of the objective function (cf. Table 7).

It becomes clear that the decreasing risk position as to the ITSP is "bought" at the cost of a lower 
Table 6 Tableau of results for the case example as to $b=80$ (strongly risk-averse decision-maker)

\begin{tabular}{|c|c|c|c|c|c|c|c|c|c|}
\hline \multirow[t]{2}{*}{ Decision point (DP) $t$} & \multicolumn{3}{|l|}{$t=0$} & \multicolumn{3}{|l|}{$t=1$} & \multicolumn{3}{|l|}{$t=2$} \\
\hline & Supplier 1 & Supplier 2 & Supplier 3 & Supplier 1 & Supplier 2 & Supplier 3 & Supplier 1 & Supplier 2 & Supplier 3 \\
\hline Process action 1 & 0 & 0 & 1 & 0 & 0 & 1 & 0 & 0 & 1 \\
\hline Process action 2 & 1 & 0 & 0 & 1 & 0 & 0 & 1 & 0 & 0 \\
\hline Process action 3 & 0 & 0 & 0 & 0 & 0 & 0 & 0 & 0 & 0 \\
\hline Process action 4 & - & - & - & 0 & 0 & 0 & 0 & 0 & 1 \\
\hline Process action 5 & - & - & - & 0.25 & 0.75 & 0 & 0.25 & 0.75 & 0 \\
\hline Process action 6 & - & - & - & 0 & 0 & 0 & 0 & 0 & 0 \\
\hline Process action 7 & - & - & - & - & - & - & 0 & 0 & 0 \\
\hline Process action 8 & - & - & - & - & - & - & 0.50 & 0.50 & 0 \\
\hline Process action 9 & - & - & - & - & - & - & 0 & 0 & 0 \\
\hline Exploited budget & \multicolumn{3}{|c|}{$2000(100 \%)$} & \multicolumn{3}{|c|}{$1700(56.7 \%)$} & \multicolumn{3}{|c|}{$1700(65.7 \%)$} \\
\hline
\end{tabular}

Table 7 Aggregation of the periodical ITSP optimization

\begin{tabular}{llll}
\hline Attitude towards risk & Risk-neutral & Risk-averse & Strongly risk-averse \\
\hline Risk aversion parameter $b$ & 0 & 40 & 80 \\
Expected present value $\hat{\mu}_{P}$ & 34984.81 & 24674.97 & 18628.28 \\
Portfolio risk $\hat{\sigma}_{P}^{2}$ & 1871.10 & 718.82 & 397.54 \\
Objective function value $\varphi\left(\hat{\mu}_{P}, \hat{\sigma}_{P}\right)$ & 34984.81 & 10298.43 & 2726.68 \\
Return/risk $\hat{\mu}_{P} / \hat{\sigma}_{P}^{2}$ & 18.70 & 34.33 & 46.86 \\
\hline
\end{tabular}

expected present value. However, if the return/risk ratio is considered, then it becomes apparent that the risk-neutral decision-maker achieves a considerably worse return per risk unit than the risk-averse or the strongly risk-averse decision-maker does. If there is e.g., only little equity capital that can be used for covering the risk, the favorable return/risk ratio in case of risk aversion can be advantageous in many cases. In contrast to the presented procedure model, general procedures used for the valuation of investments often assume that there are no diversification effects (cf. discussion in Sect. 2). In order to analyze this effect, an ITSP optimization using a fictitiously assumed correlation coefficient of $\rho\left(s_{m, n_{i}}, s_{m, n_{j}}\right)=1$ as well as $\rho\left(s_{m_{k}, n}, s_{m_{l}, n}\right)=1$ was carried out (cf. assumptions A.9 and A.10). After the aggregation of the periodical ITSP optimization, the value of the objective function was determined by taking the data of the case example as a basis. This resulted for, e.g., $b=40$ in an objective function value of $\varphi\left(\hat{\mu}_{P}, \hat{\sigma}_{P}\right)=$ 9319.25 , which was more than $9 \%$ lower.
To sum up, it can be said that a consideration of the default risk in the ITSP and, consequently, the executions of individual process actions by more internal and/or external suppliers become more important, the higher the underlying intensity of the risk aversion parameter is. As to the financial services provider, it became apparent that the original intention of concentrating on only one supplier per IT service in the course of a SOA adoption cannot entirely be assessed as being as positive as expected: On the one hand there is the cost saving effect and on the other hand there is a higher risk position which more than compensates the cost saving effect. Especially in case of the process actions "show share signals" and "determine opportunities/risks", which can be directly accessed by the customers and which may be decisive for the success, these findings contributed to the decision to employ two suppliers for each process action - despite higher costs (strongly riskaverse solution). Thus, the results reflect the influence of the decision-maker's risk aversion on the decision-making process, with the results achieved in this case example being strongly dependent on the individual situation of the financial services provider in question (cf. March and
Shapira 1987). In addition, some findings can partly be explained in connection with the selected modeling. For this reason, the transferability of the results has to be assessed individually and critically for each case.

\section{Summary, Implications, and Future Research}

In the present paper a quantitative, multi-period procedure model was developed which makes it possible to prioritize available IT services. Then a decision logic for the heuristic solution of the selection problem was presented and the practical application was demonstrated by means of an illustrative case example.

The results of the application make clear that due to the common practice of assigning an entire process - with regard to both individual process actions and process capacity - to one supplier, potential for optimization as to the ITSP's return/risk ratio may be forfeited. In the case example it could be proven that diversification can reduce the risk position in case of correlation coefficients $<1$. Moreover, the case example shows that general procedures, which do not 
consider dependencies and possible diversification effects (and thus, implicitly assume correlation coefficients $=1$ ), lead to a lower objective function value. Therefore, a misallocation of the constrained budget is usually to be expected. In addition, the degree of diversification decisively depends on the decisionmaker's risk aversion in the case analyzed. The risk-averse decision-maker tends to have fewer process actions supported by IT services and thus, potential cost savings and improvements in efficiency are not brought about. The decisionmaker also diversifies more strongly between suppliers and thus minimizes the ITSP's risk position. The exploitation of the available budgets tends to decrease as risk aversion increases. However, a closer examination of the ITSP's risk position shows that the strongly riskaverse decision-maker achieves a much more favorable ratio of return and related risk than the risk-averse or riskneutral decision-maker does. In practice, however, it is to be expected that the risk aversion captured by the Arrow-Pratt measure is not independent from the expected return. This is why alternative approaches (e.g., Jewitt 1989) could also be taken into consideration here. Also the portfolio optimization approach according to Markowitz (1952), which is the basis of the procedure model, is subject to further restrictions, which have been frequently discussed in literature (cf. Asundi and Kazman 2001; Kersten and Verhoef 2003; Verhoef 2002; Zimmermann et al. 2008). They comprise, e.g., the liquidity of the regarded IT investment objects (cf. Sect. 1), partially neglected transaction costs (cf. assumption A.4), or alternative (e.g., asymmetrical) risk measures (cf. Steinbach 2001). These restrictions provide numerous starting points for further research.

The collection of the input parameters also has to be considered critically (cf. Braunwarth and Heinrich 2008; Buhl and Heinrich 2008). In the present case example also a possibly opportunistic behavior on part of the departments and, thus, an intentional manipulation of the data basis was excluded for the sake of simplicity. Apart from the costs of implementation or integration, the expected demand, the incoming payment surplus in case of a successful execution or, respectively, additional outgoing payments in case of a non-availability of the IT service as well as the price have to be determined for each IT service. While these variables can be determined relatively easily, there are difficulties, above all, as to the determination of the expected present value and the standard deviation regarding the IT services' probabilities of availability as well as the correlations between them. By means of sensitivity analyses with regard to the IT services' expected demand, incoming payment surplus, and probability of availability as well as their correlations, it could be proven, however, that - in case of fluctuations within a range of approximately $5 \%$ - the fixed payments for investments for the implementation or integration of the IT services stabilize the determined result. Therefore, especially soft "transitions" between portfolios, in which a new supplier is considered in the ITSP only to a relatively small degree, occur only rarely in case of smaller deviations of the parameters (cf. Braunwarth and Heinrich 2008, pp. 107 f). However, in case of larger deviations within a range of $15 \%$ to $25 \%$, the divergences from the result determined before become more apparent. In addition, the transferability of these findings, which are based on a single case example, to other companies is heavily dependent on the respective situation in a company and must therefore be discussed critically. Further studies should validate the results achieved in this paper by means of both further case studies and extensive simulations. However, the algorithm we used for the ITSP optimization requires rather extensive calculations. The recurring calculations, which are due to the application of the "Add" and "Subtract" algorithm as well as the so-called Knapsack problem (cf. Appendix 1), offer starting points to improve efficiency. The authors intend to develop more efficient algorithms and heuristics that are suitable for the quality of the available data and to evaluate them with regard to larger data sets.

Despite the requirements for further research discussed above, the present paper provides initial theoretical and practical fundamental insights: Apart from the theoretical analysis of the relationship between the decision-maker's risk aversion and the resulting diversification effects in ITSPs, we presented a first approach to optimize a portfolio's composition in case of dependencies between portfolio positions and suppliers, which - inter alia - can also be found in program portfolios, engineering activities, or SOAs as examined in this paper. In accordance with our reference to future research this approach is to be developed further.

\section{Abstract \\ Florian Probst, Hans Ulrich Buhl \\ Supplier Portfolio Management for IT Services Considering Diversification Effects}

By means of service-oriented architectures the IT support of processes can be designed as a portfolio of individual IT services provided by different suppliers. The processes are designed based on selection decisions between IT services that potentially have to be included. Many companies formulate a multitude of requirements for investments in IT services at ever shorter intervals. However, the scope of the desired investments usually exceeds the available budget. Thus, companies face the challenge of allocating the limited budget to investments in the most promising combination of IT services. This is hardly possible without methodical support. In addition, the allocation is often done intuitively and subject to the decision-makers' affinity with IT. Therefore, this paper develops a quantitative, multi-period procedure model for the purpose of maximizing the enterprise value in accordance with value based management, which considers the dependencies of the periodical selection decisions. In the following, a decision logic for the heuristic solution to the selection problem is presented and its application is demonstrated by means of an illustrative case example.

Keywords: IT services, Portfolio management, Service-oriented architectures, Budget constraints, Decision logic, Value based management 


\section{Acknowledgements}

This article was supported by the DFG (Deutsche Forschungsgemeinschaft) within the project "IT Portfolio Management (ITPM)" (BU 809/10-1). We would like to take this opportunity to thank the DFG for their support. In addition, we would like to express our special thanks to Dr. Kathrin Susanne Braunwarth for her valuable comments and ideas regarding a previous version of this article.

\section{References}

Arrow KJ (1965) Aspects of the theory of risk bearing. Helsinki

Asundi J, Kazman R (2001) A foundation for the economic analysis of software architectures. In: Proceedings of the 3rd workshop on economics-driven software engineering research, Toronto

Bamberg G, Dorfleitner G, Krapp M (2006) Unternehmensbewertung unter Unsicherheit: Zur entscheidungstheoretischen Fundierung der Risikoanalyse. Z Betriebswirtsch 76(3):287-307

Bardhan I, Bagchi S, Sougstad R (2004) Prioritizing a portfolio of information technology investment projects. J Manag Inf Syst 21(2):33-60

Bellman RE (1957) Dynamic programming. Princeton University Press, Princeton

Benaroch M, Kauffman RJ (1999) A case for using real options pricing analysis to evaluate information technology project investments. Inf Syst Res 10(1):70-86

Blodig C, Heinrich B, Wehrmann A (2006) Wirtschaftlichkeitsanalyse bei der Einführung und Gestaltung von Wissensmanagementsystemen am Beispiel der Kundenserviceprozesse einer Automobilbank. In: Lehner F, Nösekabel H, Kleinschmidt P (eds) Multikonferenz Wirtschaftsinformatik, Passau, pp 473-486

Boles D, Schmees M (2003) Kostenpflichtige Web-Services. In: Uhr W, Esswein W, Schoop E (eds) Wirtschaftsinformatik 2003: Medien - Märkte - Mobilität. Physica, Heidelberg, pp 385-403

Brandl R, Bichler M, Ströbel M (2007) Cost accounting for shared IT infrastructures estimating resource utilization in distributed IT architectures. WIRTSCHAFTSINFORMATIK 49(2):83-94

Braunwarth KS, Friedl B (2010) Towards a financially optimal design of IT services. In: 31st international conference on information systems, St Louis

Braunwarth KS, Heinrich B (2008) IT-ServiceManagement - Ein Modell zur Bestimmung der Folgen von Interoperabilitätsstandards auf die Einbindung externer IT-Dienstleister. WIRTSCHAFTSINFORMATIK 50(2):98-110

Buhl HU, Heinrich B (2008) Valuing customer portfolios under risk-return-aspects: a model-based approach and its application in the financial service industry. Acad Market Sci Rev 12(5)
Buhl HU, Röglinger M, Stöckl S, Braunwarth KS (2011) Value orientation in process management. Bus Inf Syst Eng 3(3):163-172

Coenenberg A, Salfeld R (2003) Wertorientierte Unternehmensführung. SchäfferPoeschel, Stuttgart

de Reyck B, Grushka-Cockaynea Y, Lockettc M Calderinia SR, Mouraa M, Sloperb A (2005) The impact of project portfolio management on information technology projects. Int J Proj Manag 23(7):524-537

Diao Y, Bhattacharya K (2008) Estimating business value of IT services through process complexity analysis. In: Proceedings of the 11 th IEEE/IFIP network operation and management symposium, Salvador de Bahia

Diepold D, Ullrich C, Wehrmann A, Zimmermann S (2011) Bewertung intertemporaler Abhängigkeiten zwischen IT-Projekten Z Betriebswirtsch 81(7/8):805-831

Dörner W (2003) IT-Investitionen: Investitionstheoretische Behandlung von Unsicherheit. Dr Kovač, Hamburg

Dreifus F, Leyking K, Loos P (2007) Systematisierung der Nutzenpotentiale einer SOA. In: Nissen V, Petsch M, Schorcht H (eds) Service-orientierte Architekturen: Chancen und Herausforderungen bei der Flexibilisierung und Integration von Unternehmensprozessen. Gabler, Wiesbaden, pp 1938

Erl T (2005) Service-oriented architecture: concepts, technology, and design. Prentice Hall, New Jersey

Gebauer J, Lee F (2008) Enterprise system flexibility and implementation strategies aligning theory with evidence from a case study. Inf Syst Manag 25(1):71-82

Gebauer J, Schober F (2006) Information system flexibility and the cost efficiency of business processes. J Assoc Inf Syst 7(3):122-147

Hawes WM, Duffey MR (2008) Formulation of financial valuation methodologies for NASA's human spaceflight projects. Proj Manage J 39(1):85-94

Helmke S, Dangelmaier W (2008) Ganzheitliches CRM-Audit für eine erfolgreiche Einführung von CRM. In: Helmke $S$, Uebel MF, Dangelmaier W (eds) Effektives Customer Relationship Management. Gabler, Wiesbaden, pp 289-300

lqbal M, Nieves M, Taylor S (2007) Service strategy. The Stationery Office, London

IT Governance Institute (2008) IT governance global status report. Rolling Meadows

Jeffery M, Leliveld I (2004) Best practices in IT portfolio management. MIT Sloan Manag $\operatorname{Rev} 45(3): 41-49$

Jewitt I (1989) Choosing between risky prospects: the characterization of comparative statics results, and location independent risk. Manag Sci 35(1):60-70

Kargl H (2000) IV-Strategie. In: Dobschütz $L$, Barth $M$, Jäger-Goy $H$, Kütz $M$, Möller HP (eds) IV-Controlling: Konzepte - Umsetzung - Erfahrungen. Gabler, Wiesbaden, pp 39-74

Kersten B, Verhoef C (2003) IT portfolio management: a banker's perspective on IT. Cutter IT J 16(4):27-33

Kesten R, Müller A, Schröder H (2007) ITControlling: Messung und Steuerung des Wertbeitrags der IT. Vahlen, Munich

Kontogiannis K, Lewis G, Smith D (2007) The landscape of service-oriented systems: a research perspective for maintenance and reengineering. In: Proceedings of the workshop on service-oriented architecture maintenance, Amsterdam
Krafzig D, Banke K, Slama D (2007) Enterprise SOA - service-oriented architecture best practices. Prentice Hall, New Jersey

Lacity M, Willcocks L (2003) IT sourcing reflections - lessons for customers and suppliers. WIRTSCHAFTSINFORMATIK 45(2):115-125

Maizlish B, Handler R (2005) IT portfolio management: unlocking the business value of technology. Wiley, New York

March JG, Shapira Z (1987) Managerial perspectives on risk and risk taking. Manag Sci 33(11):1404-1418

Markowitz HM (1952) Portfolio selection. J Finance 7(1):77-91

Pahlke I, Wolf M, Beck R (2010) EnterpriseMashup-Systeme als Plattform für situative Anwendungen. WIRTSCHAFTSINFORMATIK 52(5):299-309

Papazoglou MP (2003) Service-oriented computing: concepts, characteristics and directions. In: Proceedings of the 4th international conference on web information systems engineering, Rome

Pratt JW (1964) Risk aversion in the small and in the large. Econometrica 32(1/2):122136

Prokein O (2008) IT-Risikomanagement Identifikation, Quantifizierung und wirtschaftliche Steuerung. Gabler, Wiesbaden

Reichmayr C (2003) Collaboration und Webservices: Architekturen, Portale, Techniken und Beispiele. Springer, Berlin

Rud D, Mencke S, Schmietendorf A, Dumke R (2007) Granularitätsmetriken für serviceorientierte Architektur. In: Tagungsband zum DASMA Metrik Kongress 2007, Kaiserslautern

Schelp J, Winter R (2007) Towards a methodology for service construction. In: Proceedings of 40th Hawaii international conference on system sciences, Hawaii

Schlittgen R (2003) Einführung in die Statistik. Oldenbourg, Munich

Schneeweiß H (1967) Entscheidungskriterien bei Risiko. Springer, Berlin

Setzer T, Bhattacharya K, Ludwig H (2008) Decision support for service transition management. In: Proceedings of the 11th IEEE/IFIP network operation and management symposium, Salvador de Bahia

Singh MP, Huhns MN (2005) Service-oriented computing: semantics, processes, agents. Wiley, Chichester

Steinbach MC (2001) Markowitz revisited: mean-variance models in financial portfolio analysis. SIAM Rev 43(1):31-85

Thomas O, vom Brocke J (2010) A valuedriven approach to the design of service oriented information systems - making use of conceptual models. Inf Syst E-Bus Manag 8(1):67-97

Trienekens JJM, Bouman JJ, van der Zwan M (2004) Specification of service level agreements: problems, principles and practices. Softw Qual J 12(1):43-57

Verhoef C (2002) Quantitative IT portfolio management. Sci Comput Program 45(1):1-96

vom Brocke J, Sonnenberg C (2007) Serviceorientiertes Prozesscontrolling Unternehmensindividuelle Wirtschaftlichkeitsrechnungen zur Nutzung serviceorientierter Architekturen bei der Prozessgestaltung. In: Nissen V, Petsch M, Schorcht $\mathrm{H}$ (eds) Service-orientierte Architekturen: Chancen und Herausforderungen bei der Flexibilisierung und Integration von Unternehmensprozessen. Gabler, Wiesbaden, pp 185-204

vom Brocke J, Sonnenberg C, Simons A (2009) Wertorientierte Gestaltung von Informationssystemen: Konzeption und Anwen- 
dung einer Potenzialmodellierung am Beispiel Serviceorientierter Architekturen. Bus Inf Syst Eng 1(3):223-233

Wehrmann A, Heinrich B, Seifert F (2006) Quantitatives IT-Portfoliomanagement: Risiken von IT-Investitionen wertorientiert steuern. WIRTSCHAFTSINFORMATIK 48(4):234-245
Zimmermann S (2008a) Governance im ITPortfoliomanagement - Ein Ansatz zur Berücksichtigung von Strategic Alignment bei der Bewertung von IT. WIRTSCHAFTSINFORMATIK 50(5):357-365

Zimmermann S (2008b) IT-Portfoliomanagement - Ein Konzept zur Bewertung und Gestaltung von IT. Inform-Spektrum 31(5):460-468

Zimmermann S, Katzmarzik A, Kundisch D (2008) IT sourcing portfolio management for IT services providers - a risk/cost perspective. In: 29th international conference on information systems, Paris 


\section{Supplier Portfolio Management for IT Services Considering Diversification Effects}

Florian Probst, Hans Ulrich Buhl

Business \& Information System Engineering (2012) 4 (2)

Appendix (available online via http://springerlink.com) 


\section{Appendix 1 - Heuristic Procedure for the Practical Application of the Model}

The optimization of the ITSP is effected at each decision point (DP) $t$ by means of the following objective function:

$$
\varphi\left(\mu_{t, P}, \sigma_{t, P}\right)=\mu_{t, P}-\frac{b}{2} \cdot \sigma_{t, P}^{2} \rightarrow \max !
$$

with the constraints:

$$
x_{\tau, m, n}=x_{h, m, n}=\text { konst. }>0 \forall \tau-1 \leq h \leq T_{m}, m, n \text {, if } h \geq 0 \text {, }
$$

with $h$ being defined as $h=\min \left\{v \in\left\{t, \ldots, T_{m}\right\}: x_{v, m, n}>0\right\}$ and

$$
\sum_{m=1}^{M} \sum_{n=1}^{N} I_{m, n} \cdot\left(1-\operatorname{sgn}\left[\left(1-\operatorname{sgn}\left[x_{t, m, n}\right]\right)+\operatorname{sgn}\left[x_{t-1, m, n}\right]\right) \leq B_{t}\right.
$$

1. [Determination of $\mu_{t, P}$ and $\sigma_{t, P}^{2}$ ] As to the determination of the optimal portfolio it is - in comparison to the objective function (3.5) with $\mu_{P}$ according to (3.2) and $\sigma_{P}^{2}$ according to (3.4) - not necessary to aggregate to $\mu_{P}$ over all DP $t$ because an optimization by means of the objective function (3.6) is effected at DP $t$ only. Instead, it is sufficient to determine the related expected present value of the ITSP $\mu_{t, P}$ and its $\sigma_{t, P}^{2}$ for each DP $t$. In case of an ITSP optimization in accordance with the objective function (3.6), the ITSP's expected present value $\mu_{t, P}$, which is aggregated over all process actions and suppliers and which is discounted to the DP $t$, thus results from the sum of the weighted expected present values of the periodical payment surpluses $\hat{\mu}_{\tau, m, n}$ of all IT services $S_{m, n}$, which have already been realized or newly requested and which are to be taken into consideration, with this sum being reduced by the payments for investments of newly requested IT services:

$$
\mu_{t, P}=\sum_{m=1}^{M} \sum_{n=1}^{N} \sum_{\tau=t+1}^{T_{m}}\left(x_{\tau, m, n} \cdot a_{\tau, m, n} \cdot \hat{\mu}_{\tau, m, n}-I_{m, n} \cdot\left(1-\operatorname{sgn}\left[\left(1-\operatorname{sgn}\left[x_{\tau, m, n}\right]\right)+\operatorname{sgn}\left[x_{\tau-1, m, n}\right] 1\right)\right)\right.
$$

with the constraints:

$$
x_{\tau, m, n}=x_{h, m, n}=\text { const. }>0 \forall \tau-1 \leq h \leq T_{m}, m, n \text {, if } h \geq 0 \text {, }
$$

with $h$ being defined as $h=\min \left\{v \in\left\{t, \ldots, T_{m}\right\}: x_{v, m, n}>0\right\}$.

The expected present values of the periodical payment surpluses $\hat{\mu}_{\tau, m, n}$ can be determined as follows:

$$
\hat{\mu}_{\tau, m, n}=\frac{d_{\tau, m} \cdot q_{\tau, m} \cdot\left(E\left(\tilde{w}_{m, n}\right) \cdot r_{\tau, m, n}+\left(1-E\left(\tilde{w}_{m, n}\right)\right) \cdot\left(r_{\tau, m, n}-k_{\tau, m, n}\right)\right)}{\left(1+i_{\text {calc }}\right)^{\tau-t}}
$$


However, it is to be observed that - in contrast to formula (3.1) - the advance payment surpluses are discounted to the respective DP $t$ instead of the uniform point in time $t=0$. The related portfolio risk results from the sum of the weighted covariances corresponding to formula (3.4):

$$
\sigma_{t, P}^{2}=\sum_{m_{k}=1 n_{i}=1}^{M} \sum_{\tau_{p}=t+1}^{N} \sum_{m_{l}=1 n_{j}=1}^{T_{m_{q}}} \sum_{\tau_{q}=t+1}^{N} x_{\tau_{p}, m_{k}, n_{i}}^{T_{m}} \cdot a_{\tau_{p}, m_{k}, n_{i}} \cdot x_{\tau_{q}, m_{l}, n_{j}} \cdot a_{\tau_{q}, m_{l}, n_{j}} \cdot \hat{\sigma}_{\tau_{p}, m_{k}, n_{i}} \cdot \hat{\sigma}_{\tau_{q}, m_{l}, n_{j}} \cdot \rho\left(s_{m_{k}, n_{i}}, s_{m_{l}, n_{j}}\right)
$$

with the constraints:

$$
x_{\tau, m, n}=x_{h, m, n}=\text { const. }>0 \forall \tau-1 \leq h \leq T_{m}, m, n \text {, if } h \geq 0,
$$

with $h$ being defined as $h=\min \left\{v \in\left\{t, \ldots, T_{m}\right\}: x_{v, m, n}>0\right\}$,

with the standard deviation $\hat{\sigma}_{\tau, m, n}$, which is necessary for the determination of the portfolio risk, being calculated as follows:

$$
\hat{\sigma}_{\tau, m, n}=\frac{d_{\tau, m} \cdot q_{\tau, m} \cdot k_{\tau, m, n}}{\left(1+i_{\text {calc }}\right)^{\tau-t}} \cdot \sqrt{\operatorname{Var}\left(\widetilde{w}_{m, n}\right)} .
$$

Again, discounting is effected at DP $t$.

2. [Execution of the ITSP optimization] In order to fulfill the objective function formulated in (3.6) proximately, we have to calculate all possible combinations of potentially supportable process actions and - due to correlations between the probabilities of availability - of process actions that have already been supported for each DP $t .{ }^{1}$ Due to the inclusion of outgoing payments for investments which are independent from the actual share of an IT service in a portfolio there is a jump discontinuity as to each of these calculations. As a result, the objective function is neither continuous nor differentiable. Thus, the general Markowitz algorithm (Markowitz 1952), which is usually used for the optimization of portfolios, cannot be applied. Kellerer et al. (2000) deal with this issue and show that this is a NP-hard problem. A complete enumeration of all possible portfolio combinations cannot be provided in this context because in case of $M$ process actions and $N$ suppliers, a calculation of $\left(2^{N}-1\right)^{M}$ portfolios is necessary if the supply matrix is complete. However, on the basis of the input parameters for $\hat{\mu}_{\tau, m, n}$ and $\hat{\sigma}_{\tau, m, n}$, which were determined in step 1, a heuristic solution to the optimization problem can be determined for each combination - e.g., by using

1 In a broader sense, this is a Knapsack problem. The efficient solution of Knapsack problems in general is not to be discussed in the following because there is already a multitude of heuristics and algorithms which were developed for the efficient solution of these problems. As to that an overview is provided by, e.g., Kellerer et al. (2004), Martello and Toth (1990), and Beier and Vöcking (2004), who have shown - on the basis of the Nemhauser/Ullmann algorithm (Nemhauser and Ullmann 1969) - that, usually, Knapsack problems of the above mentioned type can still be solved in polynomial time. 
the "Add" and "Subtract" algorithm (cf. Buhl and Heinrich 2008) - while taking the outgoing payments for investments into account. But, since the idea of the ITSP is the essential subject of this paper, this problem will not be further discussed.

Steps 1 and 2 are to be effected at each DP $t$ until the end of the planning horizon at the point in time $T$.

3. [Aggregation of the results of the periodical ITSP optimization] In order to aggregate the results of the single-period ITSP optimization over the entire planning horizon until its final point in time $T$, the present values of the selected IT services - which are discounted to $t=0$ - are calculated over the entire period until the point in time $T_{m}$. The weights of the share of all IT services which are newly requested at DP $t$ and the weights of the share of the IT services which have already been realized at the point in time $t=0$ and which have not been removed yet at the first effectivity point (EP) $t=1$ were determined in step 2. Taking this as a basis, the expected present value of the ITSP $\hat{\mu}_{P}$ and the portfolio risk $\hat{\sigma}_{P}^{2}$ can be determined over all DP $t$ of the planning horizon - using formula (3.2) for the present value and formula (3.4) for the portfolio risk. Thus, the value of the objective function can be determined - while taking the decision-maker's attitude towards risk into consideration - by using the preference function $\varphi\left(\hat{\mu}_{P}, \hat{\sigma}_{P}\right)=\hat{\mu}_{P}-\frac{b}{2} \cdot \hat{\sigma}_{P}^{2}$ in accordance with the optimization problem in (3.5). For this purpose, the same risk aversion parameter $b$, which was used - by means of the objective function (3.6) - for the underlying single-period ITSP optimizations, has to be applied.

\section{References}

Beier R, Vöcking B (2004) Random knapsack in expected polynomial time. J Comput. Sys. Sci. 69(3):306-329

Buhl HU, Heinrich B (2008) Valuing customer portfolios under risk-return-aspects: a modelbased approach and its application in the financial service industry. Acad. Market. Sci. Rev. 12(5)

Kellerer H, Mansini R, Speranza G (2000) Selecting portfolios with fixed costs and minimum transaction lots. Ann. Oper. Res. 99(1):287-304

Kellerer H, Pferschy U, Pisinger D (2004) Knapsack Problems. Springer, Berlin

Markowitz HM (1952) Portfolio selection. J. Fin. 7(1):77-91

Martello S, Toth P (1990) Knapsack problems: algorithms and computer implementations. Wiley, Chichester

Nemhauser G, Ullmann Z (1969) Discrete dynamic programming and capital allocation. Manag. Sci. 15(9):494-505 


\section{Appendix 2 - Data which the Case Example is Based on}

Input data of the IT services $s_{m, n}$ which are identified at the first decision point (DP) $t=0$ and which are employed for the support of the process actions $m=1,2,3$ of the suppliers $n=1,2,3$

Expected demand $d_{t, m} \cdot q_{t, m}$ after the process actions $m=1,2,3$

\begin{tabular}{|l|c|c|c|c|c|c|}
\hline Point in time $t$ & $t=1$ & $t=2$ & $t=3$ & $t=4$ & $t=5$ & $t=T_{m}=6$ \\
\hline Expected demand $d_{t, 1} \cdot q_{t, 1}$ & 7200 & 8100 & 10800 & 10800 & 10800 & 10800 \\
\hline Expected demand $d_{t, 2} \cdot q_{t, 2}$ & 5950 & 5100 & 5525 & 5950 & 6375 & 6800 \\
\hline Expected demand $d_{t, 3} \cdot q_{t, 3}$ & 6000 & 6800 & 6400 & 6400 & 6000 & 6400 \\
\hline
\end{tabular}

Outgoing payments for investments $I_{m, n}$ for the design or, inclusion of an IT Service $s_{m, n}$

\begin{tabular}{|l|c|c|c|}
\hline Supplier $n$ & Supplier 1 (external) & Supplier 2 (external) & Supplier 3 (own IT subsidiary) \\
\hline Payments for investments $I_{1, n}$ & 1100 & 1000 & 1200 \\
\hline Payments for investments $I_{2, n}$ & 800 & 900 & 800 \\
\hline Payments for investments $I_{3, n}$ & 800 & 1000 & 1000 \\
\hline
\end{tabular}

Incoming payment surplus $r_{t, m, n}$ in case of a successful execution of the IT service $s_{m, n}$ for $t=1, \ldots, 6$

\begin{tabular}{|l|c|c|c|}
\hline Supplier $n$ & Supplier 1 (external) & Supplier 2 (external) & Supplier 3 (own IT subsidiary) \\
\hline Payment surplus $r_{t, 1, n}$ & 0.16 & 0.15 & 0.20 \\
\hline Payment surplus $r_{t, 2, n}$ & 0.16 & 0.18 & 0.21 \\
\hline Payment surplus $r_{t, 3, n}$ & 0.17 & 0.19 & 0.21 \\
\hline
\end{tabular}

Expected availability $E\left(\widetilde{w}_{m, n}\right)$ of an IT service $s_{m, n}$ and its variance $\operatorname{Var}\left(\widetilde{w}_{m, n}\right)$

\begin{tabular}{|l|c|c|c|}
\hline Supplier $n$ & Supplier 1 (extern) & Supplier 2 (extern) & Supplier 3 (own IT subsidiary) \\
\hline $\begin{array}{l}\text { Expected availability } E\left(\tilde{w}_{1, n}\right) \text { and } \\
\text { its variance } \operatorname{Var}\left(\tilde{w}_{1, n}\right)\end{array}$ & $0.99 / 0.000020$ & $0.95 / 0.000023$ & $0.93 / 0.000012$ \\
\hline $\begin{array}{l}\text { Expected availability } E\left(\tilde{w}_{2, n}\right) \text { and } \\
\text { its variance } \operatorname{Var}\left(\tilde{w}_{2, n}\right)\end{array}$ & $0.99 / 0.000015$ & $0.95 / 0.000012$ & $0.93 / 0.000024$ \\
\hline $\begin{array}{l}\text { Expected availability } E\left(\tilde{w}_{3, n}\right) \text { and } \\
\text { its variance } \operatorname{Var}\left(\tilde{w}_{3, n}\right)\end{array}$ & $0.99 / 0.000025$ & $0.95 / 0.000022$ & $0.93 / 0.000032$ \\
\hline
\end{tabular}

Outgoing payments $k_{t, m, n}$ in case of a non-availability of an IT service $s_{m, n}$ for $t=1, \ldots, 6$ (already reduced by possible penalty payments)

\begin{tabular}{|l|c|c|c|}
\hline Supplier $n$ & Supplier 1 (extern) & Supplier 2 (extern) & Supplier 3 (own IT subsidiary) \\
\hline $\begin{array}{l}\text { Costs in case of } \\
\text { non-availability } k_{t, 1, n}\end{array}$ & 16 & 15 & 20 \\
\hline $\begin{array}{l}\text { Costs in case of } \\
\text { Non-availability } k_{t, 2, n}\end{array}$ & 15 & 20 & 17 \\
\hline $\begin{array}{l}\text { Costs in case of } \\
\text { non-availability } k_{t, 3, n}\end{array}$ & 15 & 20 & 22 \\
\hline
\end{tabular}


Input data of the IT services $s_{m, n}$ which are identified at the second DP $t=1$ for the support of the process actions $m=4,5,6$ of the suppliers $n=1,2,3$

Expected demand $d_{t, m} \cdot q_{t, m}$ after the process actions $m=4,5,6$

\begin{tabular}{|l|c|c|c|c|c|c|}
\hline Point in time $t$ & $t=1$ & $t=2$ & $t=3$ & $t=4$ & $t=5$ & $t=T_{m}=6$ \\
\hline Expected demand $d_{t, 4} \cdot q_{t, 4}$ & 9500 & 11400 & 14250 & 14250 & 15200 & 15200 \\
\hline Expected demand $d_{t, 5} \cdot q_{t, 5}$ & 6800 & 5950 & 8750 & 8500 & 8500 & 8500 \\
\hline Expected demand $d_{t, 6} \cdot q_{t, 6}$ & 7125 & 7125 & 7500 & 8250 & 9750 & 9750 \\
\hline
\end{tabular}

Outgoing payments for investments $I_{m, n}$ for the design or inclusion of an IT service $s_{m, n}$

\begin{tabular}{|l|c|c|c|}
\hline Supplier $n$ & Supplier 1 (external) & Supplier 2 (external) & Supplier 3 (own IT subsidiary) \\
\hline Payments for investments $I_{4, n}$ & 900 & 1000 & 1200 \\
\hline Payments for investments $I_{5, n}$ & 800 & 900 & 1100 \\
\hline Payments for investments $I_{6, n}$ & 1200 & 1200 & 1300 \\
\hline
\end{tabular}

Incoming payment surplus $r_{t, m, n}$ in case of a successful execution of the IT service $s_{m, n}$ for $t=2, \ldots, 7$

\begin{tabular}{|l|c|c|c|}
\hline Supplier $n$ & Supplier 1 (external) & Supplier 2 (external) & Supplier 3 (own IT subsidiary) \\
\hline Payment surplus $r_{t, 4, n}$ & 0.10 & 0.13 & 0.15 \\
\hline Payment surplus $r_{t, 5, n}$ & 0.12 & 0.15 & 0.19 \\
\hline Payment surplus $r_{t, 6, n}$ & 0.17 & 0.20 & 0.23 \\
\hline
\end{tabular}

Expected availability $E\left(\widetilde{w}_{m, n}\right)$ of an IT service $s_{m, n}$ and its variance $\operatorname{Var}\left(\widetilde{w}_{m, n}\right)$

\begin{tabular}{|l|c|c|c|}
\hline Supplier $n$ & Supplier 1 (external) & Supplier 2 (external) & Supplier 3 (own IT subsidiary) \\
\hline $\begin{array}{l}\text { Expected availability } E\left(\tilde{w}_{4, n}\right) \text { and } \\
\text { its variance } \operatorname{Var}\left(\tilde{w}_{4, n}\right)\end{array}$ & $0.99 / 0.000020$ & $0.95 / 0.000023$ & $0.93 / 0.000012$ \\
\hline $\begin{array}{l}\text { Expected availability } E\left(\tilde{w}_{5, n}\right) \text { and } \\
\text { its variance } \operatorname{Var}\left(\tilde{w}_{5, n}\right)\end{array}$ & $0.99 / 0.000015$ & $0.95 / 0.000012$ & $0.93 / 0.000024$ \\
\hline $\begin{array}{l}\text { Expected availability } E\left(\tilde{w}_{6, n}\right) \text { and } \\
\text { its variance } \operatorname{Var}\left(\tilde{w}_{6, n}\right)\end{array}$ & $0.99 / 0.000025$ & $0.95 / 0.000022$ & $0.93 / 0.000032$ \\
\hline
\end{tabular}

Outgoing payments $k_{t, m, n}$ in case of a non-availability of an IT service $s_{m, n}$ for $t=2, \ldots, 7$ (already reduced by possible penalty payments)

\begin{tabular}{|l|c|c|c|}
\hline Supplier $n$ & Supplier 1 (external) & Supplier 2 (external) & Supplier 3 (own IT subsidiary) \\
\hline $\begin{array}{l}\text { Costs in case of } \\
\text { non-availability } k_{t, 4, n}\end{array}$ & 16 & 15 & 20 \\
\hline $\begin{array}{l}\text { Costs in case of } \\
\text { non-availability } k_{t, 5, n}\end{array}$ & 15 & 20 & 17 \\
\hline $\begin{array}{l}\text { Costs in case of } \\
\text { non-availability } k_{t, 6, n}\end{array}$ & 15 & 20 & 22 \\
\hline
\end{tabular}


Input data of the IT services $s_{m, n}$ which are identified at the third DP $t=2$ for the support of the process actions $m=7,8,9$ of the suppliers $n=1,2,3$

Expected demand $d_{t, m} \cdot q_{t, m}$ after the process actions $m=7,8,9$

\begin{tabular}{|l|c|c|c|c|c|c|}
\hline Point in time $t$ & $t=1$ & $t=2$ & $t=3$ & $t=4$ & $t=5$ & $t=T_{m}=6$ \\
\hline Expected demand $d_{t, 7} \cdot q_{t, 7}$ & 7650 & 8100 & 10800 & 11700 & 12600 & 13500 \\
\hline Expected demand $d_{t, 8} \cdot q_{t, 8}$ & 5525 & 6375 & 5950 & 5950 & 5525 & 5525 \\
\hline Expected demand $d_{t, 9} \cdot q_{t, 9}$ & 9025 & 9500 & 10450 & 10450 & 11875 & 12350 \\
\hline
\end{tabular}

Outgoing payments for investments $I_{m, n}$ for the design or, inclusion of an IT service $s_{m, n}$

\begin{tabular}{|l|c|c|c|}
\hline Supplier $n$ & Supplier 1 (external) & Supplier 2 (external) & Supplier 3 (own IT subsidiary) \\
\hline Payments for investments $I_{7, n}$ & 1000 & 1000 & 1200 \\
\hline Payments for investments $I_{8, n}$ & 800 & 900 & 900 \\
\hline Payments for investments $I_{9, n}$ & 1300 & 1500 & 1600 \\
\hline
\end{tabular}

Incoming payment surplus $r_{t, m, n}$ in case of a successful execution of the IT service $s_{m, n}$ for $t=3, \ldots, 8$

\begin{tabular}{|l|c|c|c|}
\hline Supplier $n$ & Supplier 1 (external) & Supplier 2 (external) & Supplier 3 (own IT subsidiary) \\
\hline Payment surplus $r_{t, 7, n}$ & 0.14 & 0.15 & 0.18 \\
\hline Payment surplus $r_{t, 8, n}$ & 0.15 & 0.18 & 0.20 \\
\hline Payment surplus $r_{t, 9, n}$ & 0.17 & 0.19 & 0.21 \\
\hline
\end{tabular}

Expected availability $E\left(\widetilde{w}_{m, n}\right)$ of an IT service $s_{m, n}$ and its variance $\operatorname{Var}\left(\widetilde{w}_{m, n}\right)$

\begin{tabular}{|l|c|c|c|}
\hline Supplier $n$ & Supplier 1 (external) & Supplier 2 (external) & Supplier 3 (own IT subsidiary) \\
\hline $\begin{array}{l}\text { Expected availability } E\left(\tilde{w}_{7, n}\right) \text { and } \\
\text { its variance } \operatorname{Var}\left(\tilde{w}_{7, n}\right)\end{array}$ & $0.99 / 0.000020$ & $0.95 / 0.000023$ & $0.93 / 0.000012$ \\
\hline $\begin{array}{l}\text { Expected availability } E\left(\tilde{w}_{8, n}\right) \text { and } \\
\text { its variance } \operatorname{Var}\left(\tilde{w}_{8, n}\right)\end{array}$ & $0.99 / 0.000015$ & $0.95 / 0.000012$ & $0.93 / 0.000024$ \\
\hline $\begin{array}{l}\text { Expected availability } E\left(\tilde{w}_{9, n}\right) \text { and } \\
\text { its variance } \operatorname{Var}\left(\tilde{w}_{9, n}\right)\end{array}$ & $0.99 / 0.000025$ & $0.95 / 0.000022$ & $0.93 / 0.000020$ \\
\hline
\end{tabular}

Outgoing payments $k_{t, m, n}$ in case of a non-availability of an IT service $s_{m, n}$ for $t=3, \ldots, 8$ (already reduced by possible penalty payments)

\begin{tabular}{|l|c|c|c|}
\hline Supplier $n$ & Supplier 1 (external) & Supplier 2 (external) & Supplier 3 (own IT subsidiary) \\
\hline $\begin{array}{l}\text { Costs in case of } \\
\text { non-availability } k_{t, 7, n}\end{array}$ & 16 & 15 & 20 \\
\hline $\begin{array}{l}\text { Costs in case of } \\
\text { non-availability } k_{t, 8, n}\end{array}$ & 15 & 20 & 17 \\
\hline $\begin{array}{l}\text { Costs in case of } \\
\text { non-availability } k_{t, 9, n}\end{array}$ & 15 & 18 & 20 \\
\hline
\end{tabular}


Correlation coefficients $\rho\left(s_{m, n}, s_{m, n}\right)$ (cf. assumptions A.9 and A.10)

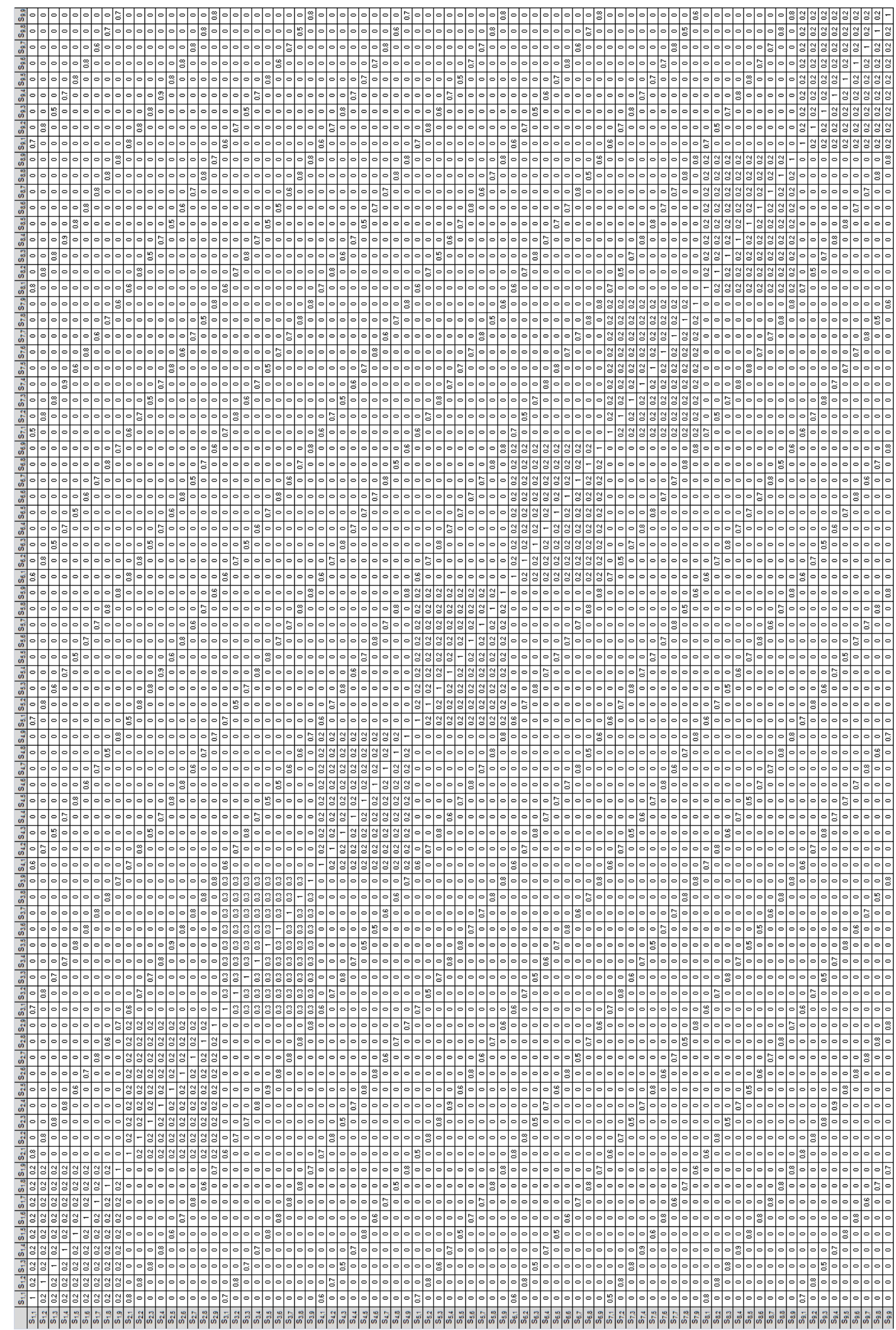

